\title{
O Sujeito refugiado-imigrante em Campanhas Digitais: a Língua Refugiada na Pesquisa em Comunicação no Brasil ${ }^{1}$
}

\author{
Dra. Rosane da Conceição Pereira², Escola Técnica Estadual Adolpho Bloch \\ da Fundação de Apoio à Escola Técnica, Brasil \\ Recibido: $\quad 31$ de marzo, 2018. \\ Aceptado: $\quad 2$ de setiembre, 2018.
}

\section{Resumo}

O estudo é uma análise discursiva crítica sobre o panorama da pesquisa em Comunicação Social no Brasil. Trata-se de um desafio porque o campo de estudo é amplo e não se restringe às suas habilitações e ofícios. Renova-se a cada dia, em função da sociedade da informação (tecnologia) e de mercado (consumo) na qual nos encontramos. Como objeto, analisa campanhas que tratam da formahistórica do sujeito refugiado para o estrangeiro e imigrante para brasileiros, segundo processos de identificação, contra-identificação e desidentificação na linguagem verbal e não verbal de vídeos e posts em sites e em rede social.

\section{Abstract}

The refugee-immigrant subject in Digital Campaigns: the Refugee Language in Communication Research in Brazil

This study is a critical discursive analysis about the panorama of research in Social Communication in Brazil. This approach poses a challenge, since the field of study is broad and not restricted to its qualifications and skills. It renews itself on a daily basis, depending on the information society (technology) and the market (consumption) in which we find ourselves. As an object, it analyzes campaigns that deal with the historical figure of the refugee considered a foreigner and an immigrant by Brazilians, according to processes of identification, counter-identification and deactivation in the verbal and non-verbal language in videos and posts on websites and in social media.

1 O artigo é inspirado em uma palestra sobre o panorama da comunicação contemporânea no III NECP da UNIVERSO (2014), coordenado pela professora Regina Coeli Vieira da Silveira e Silva, e em uma proposta de estudo para um projeto sobre língua, violência, refugiados, língua de herança, línguas em contato, língua dominante e línguas minoritárias, com a professora Tania Conceição Clemente de Souza, que o apresentou em parte no VI SIMELP (2017).

2 Profa. Dra. formada em Comunicação Social e em Linguística, Letras e Artes, na Universidade Federal Fluminense (UFF). Leciona no ensino superior em Comunicação Social, na Universidade Salgado de Oliveira (UNIVERSO), Brasil, e no ensino médio-técnico integrado profissionalizante em Publicidade e em Marketing da Escola Técnica Estadual Adolpho Bloch da Fundação de Apoio à Escola Técnica (ETEAB, FAETEC). Contato: rosadosol@yahoo. com.br.
Rosane da Conceição Pereira. O Sujeito refugiado-imigrante em Campanhas Digitais: a Língua Refugiada na Pesquisa em Comunicaçãono Brasil. Revista Comunicación. Año 39, volumen 27, número 2, julio-diciembre, 2018. Instituto Tecnológico de Costa Rica. ISSN: 0379-3974 / e-ISSN1659-3820.
PALAVRAS-CHAVE:

análise discursiva crítica, comunicação social, panorama da pesquisa.

\section{KEY WORDS:}

critical discursive analysis, social communication, research landscape. 


\section{INTRODUÇÃO}

\section{É também a sociedade que é a condição da linguagem}

(Benveniste, 1995, p. 67)

Este artigo resulta de um estudo iniciado para a palestra de abertura, intitulada Panorama da Pesquisa em Comunicação Social no Brasil, no evento III Seminário do Núcleo de Estudos em Comunicação \& Pesquisa - III NECP, realizado em 12 de maio de 2014, na Universidade Salgado de Oliveira UNIVERSO, Campus Niterói; e posteriormente de uma atualização desse estudo para a integração a um projeto desenvolvido pela professora Tania Conceição Clemente de Souza, apresentado em parte por esta última no VI Simpósio Mundial de Estudos da Língua Portuguesa - VI SIMELP, Escola Superior de Educação de Santarém, Portugal (Souza, 2017), a sair nos Anais do evento.

O tema passa da comunicação linguística (Souza, 2016), que abrange duas línguas oficiais no Brasil (o português e a Língua Brasileira de Sinais - LIBRAS), à proposta de análise do que é denominado de "língua refugiada" no discurso publicitário brasileiro, conforme a Análise do Discurso francesa, ou seja, sobre sentidos possíveis de identificações, contraidentificações e desidentificações (Pêcheux, 1988) das línguas oficiais quanto às línguas de imigrantes e de refugiados estrangeiros. Questiona-se o uso das palavras refugiado e imigrante em propagandas veiculas na internet, por meio de campanhas digitais governamentais e não governamentais, e o quais sentidos se pode inferir de refugiado nas campanhas estrangeiras e de imigrante nas campanhas nacionais, para o refugiado a ser acolhido no Brasil.

Em 2016, eram quase 8 mil refugiados registrados no país e 28 mil solicitando refúgio, conforme dados de instituições que promoveram campanhas publicitárias veiculadas em redes sociais a serem analisadas, como as campanhas Meu Amigo Refugiado (ONG Migraflix, 2016) e O que levaram com eles. \#ComOsRefugiados (UNHCRACNUR Américas / ONU, 2016); bem como duas campanhas do Ministério da Justica brasileiro, $A$ imigração está no nosso sangue e Eu também sou imigrante, segundo o jornal O Globo (2015) e o Facebook do Ministério da Justiça (2015).

Destaca-se que Instituições Sociais estrangeiras (UNHCR-ACNUR Américas e ONU, 2016) costumam designar os sujeitos históricos como Refugiados, enquanto Instituições Nacionais os tratam como Imigrantes $(\mathrm{O}$ Globo e Ministério da Justiça, 2015), como se no país houvesse um apagamento real das condições de produção materiais que os levam a sair de seus países (guerra, ideologia, religião, preconceito, dentre outras).

\section{FOCO EM PESQUISA: SOCIEDADE, CULTURA E NAÇÃO}

Note-se que o comunicador em formação lida com o discurso (efeito de sentido) da Comunicação (instituído na forma de ciências humanas e sociais), com o discurso sobre ela (pode ser o senso comum e o pragmático) e com o discurso para falar de sociedade, cultura e nação ao outro (sujeito consciente e dividido pelo inconsciente, formasujeito sem simbolização a priori).

No Brasil, afigura-se bem-vinda e oportuna a iniciativa de o professor conduzir o estudante de Comunicação Social a aprender a pensar, sem mitificações, o povo e o país como sociedade, cultura e nação. Para falar deles e, sobretudo, para falar a eles será preciso conhecê-los bem, "chegar junto"; portanto, não há motivos para guardar distância (Polistchuk e Trinta, 2003, p. 8).

Uma análise crítica do discurso sobre desenvolvimento cultural e progresso social fundamenta-se em abordagens teóricas e metodológicas de autores que pensam a Comunicação como campo de ruptura epistemológica (competências, teorias que se ressignificam) e efeito de sentido ou não verdade absoluta (habilidades, práticas ideologizadas, historicizadas, inconscientes), tais como Nietzsche, Foucault, Deleuze, Pêcheux, Lacan, entre outros.

Em suas lições e no desenvolvimento de suas atividades de pesquisa, a educação de nível universitário encerra um 
propósito fundamental. Tem por finalidade precípua a intenção de contribuir para o aperfeiçoamento de profissionais de Comunicação, seja em seus aspectos científicos, tecnológicos e éticos, seja no que respeita à sensibilidade manifesta a tudo o que signifique desenvolvimento cultural e progresso social (Polistchuk e Trinta, 2003, p. 8).

\section{PANORAMA DA PESQUISA EM COMUNICAÇÃO SOCIAL NO BRASIL: O DESAFIO}

Traçar um Panorama da Pesquisa em Comunicação Social no Brasil é um desafio porque o campo de estudo é infinito e não se restringe às suas habilitações e ofícios, renovando-se a cada dia, em função da sociedade da informação (tecnologia) e de mercado (consumo) na qual nos encontramos.

O estudo científico da Comunicação se fundamenta em um conjunto de saberes e práticas pertinentes a diversas disciplinas e pertencentes a distintos campos. (...) A tentação (e as muitas tentativas) de se fragmentar o estudo da Comunicação, especializando suas práticas por habilitações e ofícios, pode ser explicada pelo volume de solicitações que, nesse sentido, chegam ao mercado de trabalho. (...) Aquelas proposições científicas que muitos têm chamado de Ciências da Comunicação compõem um conjunto de conhecimentos de ordem inter- e pluridisciplinar em permanente processo de atualização, ao qual os teóricos da Comunicação recorrem para identificar, definir, conceituar, descrever e analisar a ação social comunicativa (Polistchuk e Trinta, 2003, p. 26).

- Panorama (modelos de pensamento em uma área como a Comunicação Social, a partir do qual podem ser relacionados Paradigmas a Tendências): Teoria + Prática (Pereira, 2014).

- Paradigmas (modelos teóricos para estudo da sociedade): Teorias (Polistchuk e Trinta, 2003).
- Tendências (modelos de comportamento sobre a praxis social): Práticas (Macroplan, 2011).

Principais paradigmas (modelos teóricos para estudo da sociedade): Teorias (Polistchuk e Trinta, 2003):

- Conceitual ou Crítico-Radical (cerca de 1923, com a Escola de Frankfurt).

- Funcionalista Pragmático (cerca de 1930, com Harold Lasswell).

- Matemático-Informacional (cerca de 1949, com Claude Shannon e Warren Weaver).

- Conflitual-Dialético (cerca de 1950, com Karl Marx).

- Culturológico (cerca de 1962, com Edgar Morin).

- Midiológico (cerca de 1970, com Herbert Marshall McLuhan).

- Novo Paradigma Horizontal-Interacionista (cerca de 1990, com Pierre Lévy, Paul Virilio e outros, sobre o homem e Novas Tecnologias de Informação e Comunicação - TICs).

Alguns desafios podem ser: a mudança das análise da produção para o conhecimento, abrindo novos segmentos e oportunidades de pesquisas e negócios (ABRALIC, ALAIC, ANPOLL, COMPÓS, NECP, INTERCOM, SEAD, SIMELP, entre outros eventos das Áreas de Comunicação e Linguagem); a gestão da Inovação como vantagem competitiva (baixo custo com tecnologia para melhoria de vida do sujeito); a maior importância da flexibilidade (resiliência), adaptabilidade e eficiência operacional em âmbito global (baixo custo com qualidade); a demanda crescente por profissionais mais qualificados, acesso à tecnologia e inteligência de mercado; a preocupação com a questão ambiental; e as pesquisas sobre o mercado de consumo de massa brasileiro que tende a crescer (Pereira, 2016), sobretudo em mídias digitais. 
Figura 1: Principais tendências ou modelos de comportamento sobre a praxis social (Macroplan, 2011)

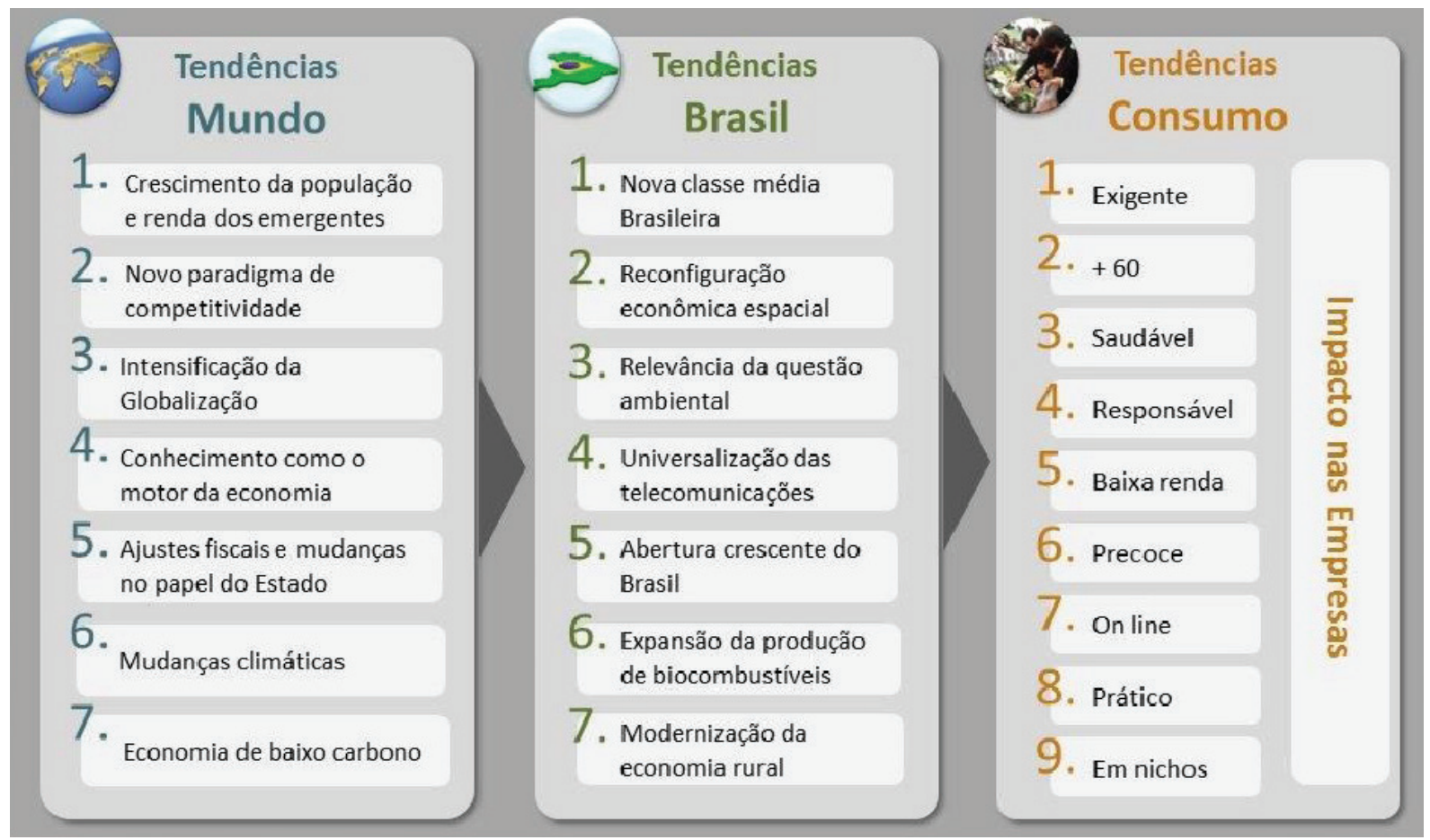

Fonte: Relatório "Tendências para os próximos 20 anos: mundo, Brasil e consumo" (Macroplan, 2011, p. 3).

\section{ANÁLISE DISCURSIVA DE CAMPANHAS DIGITAIS SOBRE A FORMA-SUJEITO REFUGIADO- IMIGRANTE: LÍNGUAS E BARREIRAS}

Uma análise crítica de campanhas publicitárias governamentais, de ONGs ou empresas sobre a questão dos refugiados no Brasil é possível, com base em conceitos da Análise do Discurso Francesa Pecheutiana (1988).

A Comunicação Social relativa aos refugiados no Brasil não possui até o momento normas quanto a campanhas publicitárias e ações de marketing em mídia impressa, eletrônica/ RTVC (rádio, televisão e cinema) e multimídia (via internet). As normas para campanhas e o uso de logomarcas do governo e de outras entidades nas campanhas existem no portal do Ministério da Saúde, por exemplo. Atualmente o Ministério da Justiça e Cidadania tem cuidado das campanhas e ações referentes aos refugiados no país e não estabelece normas sobre sua Comunicação (publicidade e marketing) em campanhas.

Contudo, o Ministério da Justiça desenvolve as campanhas "A imigração está no nosso sangue" e "Eu também sou imigrante"; enquanto Organizações Não Governamentais (ONGs), como a ação social Migraflix (com voluntários de várias nacionalidades) desenvolve o projeto "Meu amigo refugiado" no Brasil; e entidades internacionais como a UNHCR-ACNUR Américas, uma agência da Organização das Nações Unidas (ONU), possui o projeto "Com os refugiados", o qual inclui o país.

Nesse sentido, não é o foco desse estudo priorizar a legislação brasileira sobre o tema dos refugiados no Brasil (a Política). Pretende-se, portanto, analisar criticamente os gestos discursivos (o Político), ou seja, estudar os efeitos de sentido possíveis ("discurso sobre"), provenientes da enunciação nas campanhas e do silenciamento pela inexistência de normas sobre a Comunicação da temática ("discurso do" governo ou do Ministério da Justiça e Cidadania, de organizações e demais instituições sociais), enriquecendo assim o debate em termos de Política Linguística e Comunicação Social.

O que se está chamando de "língua refugiada no discurso publicitário brasileiro" pode ser assim 
estudado, sob um eixo teórico-metodológico composto por conceitos fundamentais à análise do discurso publicitário (Pereira, 2008) dos processos de identificação e alteridade pela propaganda em campanhas digitais, em sites de instituições e em redes sociais como Facebook: Trata-se, então, de trazer alguns conceitos à análise proposta.

IMIGRANTE adj. e s.m. e f. (Do lat. migrans, migrantis.) Que ou quem vem residir ou se fixa num país que não é o seu. (Antôn. EMIGRANTE.). (Grande Dicionário Larousse Cultural da Língua Portuguesa, p. 509, 1999).

REFUGIADO adj. e s.m. Diz-se de ou aquele que se afastou do local de sua residência para fugir aos efeitos da guerra, das perseguições políticas. (Grande Dicionário Larousse Cultural da Língua Portuguesa, p. 776, 1999).

Ordem Discursiva do que pode / deve ou não pode / não deve entrar na organização do discurso (Foucault, 1996) na "língua refugiada" (ou se tornar o dizível / visível pela / na língua oficial do país que acolhe o outro imigrante-refugiado).

O imigrante é todo aquele que vai residir em um país que não é o seu e o refugiado é o que imigra para fugir aos efeitos da guerra, das perseguições políticas, porque não pode / não deve ser (bem, mais) visto em seu país de nascimento por força da materialidade histórica desse contexto.

Texto da Mídia na forma-histórica do Mercado Capitalista (o anonimato forçado do sujeito refugiado ou uma invisibilidade social que significa não ter visibilidade / não ser bem sucedido, não ser) marcando a penalidade por desobedecer às leis de mercado (Payer, 2005, p. 19).

Complementação e Dissensão (Souza, 1994 apud Pereira, 2008) de sentido (imagem e texto com significação clichê, e imagem e texto com significação original em que o dito assegura o sentido do visível).

O principal objetivo é, assim, estudar a semântica do discurso publicitário (o verbal e o não verbal em campanhas publicitárias) sobre refugiados no Brasil, presentes em alguns infomerciais (comerciais na internet); além de abordar a questão linguística dos refugiados no país; e de trazer interpretações relevantes para a política linguística filiada às áreas de Comunicação Social e de Estudos Linguísticos.

Identificação (Pêcheux, 1988) à barreira da nova língua para o sujeito refugiado (construção de operadores discursivos verbais e não verbais de "tráfego" / regularidade / repetição / aproximação entre o português e a língua "do" outro).

São exemplos possíveis da identificação na ordem discursiva (o que pode / deve ser dito / tornar-se da ordem do visível), a barreira da língua portuguesa e a celebração cristã, (discurso religioso). Entretanto, nem todo refugiado seja cristão ou não comemore o Natal (dissensão do não verbal das imagens no vídeo em relação ao verbal da língua falada no vídeo), a fraternidade presente no discurso humanitário de Direitos Humanos (na campanha visualizada) aproxima os sujeitos (complementação de sentidos entre judeus e ocientais).

Figura 2: Mulher síria da campanha Meu Amigo Refugiado (ONG Migraflix, 2016)

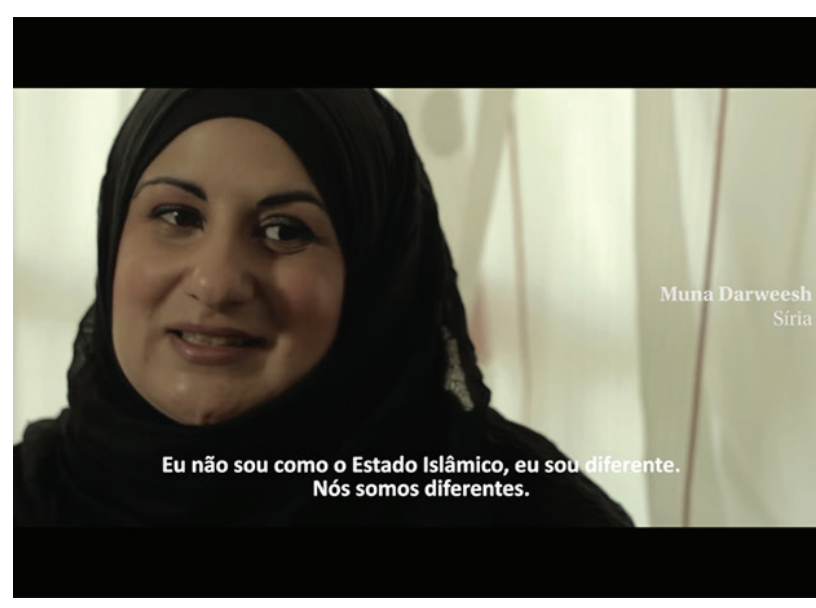

Fonte: https://youtu.be/p577E0RwKKw/

O texto da mídia digital (vídeo no site) parece cristalizar ou naturalizar a forma-histórica do sujeito refugiado em imigrante de fato (de qualquer língua, religião), embora a análise tente mostrar que ele é impelido a pertencer de direito ao contexto do sujeito de mercado na forma-histórica capitalista, ou seja, poder / dever ser como os ocidentais. 
É possível dizer que a dentificação às diferentes culturas que formam o Brasil constitui em ressonância de sentido com o caso da mulher síria da campanha, que diz não ser (como) o Estado Islâmico que ameaça a humanidade e sermos (sírios e brasileiros, islâmicos, muçulmanos ou não) diferentes. Encontramos identificações territoriais, físicas (humanas) e religiosas (metafísicas).

Contra-identificação (Pêcheux, 1988) à barreira linguística (assimilação de operadores verbais e não verbais que marquem a diferenciação / presença da língua "refugiada" no nosso discurso publicitário "sobre" ela).

A contra-identificação pode ser referida à barreira linguística e à violência bélica (armamentista, de guerras ou conflitos), opostas à petição política pelo direito à educação e à presença da "língua refugiada" nos / pelos objetos trazidos pelos imigrantes (no vídeo da campanha). Na ordem discursiva dos países que acolhem os refugiados, estes podem / devem ser (são) tratados como imigrantes (no texto da mídia digital da campanha), com direito à educação, como os brasileiros (complementação de sentido entre a linguagem verbal e a não verbal das imagens no vídeo), mas cuja dissensão de sentido se dá pelo uso da língua refugiada, ou seja, o dizer (verbal) do povo que faz brincos e joias significando a liberdade de vestir-se diferente de outros povos, como nas imagens mostradas (não verbal na campanha digital).

Tratar-se-ia de contra-identificação ou oposição à determinação do vestuário ou à moda ocidental (do brasileiro ou de outros povos), uma vez que os brincos e as joias do povo referido (aparentemente de proveniência africana) simbolizam sua liberdade de escolha, ainda que segundo regras típicas, por um lado, barreiras culturais. Mas, por outro lado, brincos e joias funcionam também como operadores discursivos da identificação desse povo em contato com diferentes formas de vestir de outros povos igualmente livres. Liberdade de vestir trajes típicos é liberdade de ser diferente entre diferentes, com formas de ensino diferentes. Enquanto um povo pode possuir tradição oral, outro se fundamenta na escrita e a língua se refugia em objetos que trazem ao imigrarem (com os refugiados).

Figura 3: Povo supostamente de proveniência africana na campanha $\mathrm{O}$ que levaram com eles. \#ComOsRefugiados (UNHCR-ACNUR Américas / ONU, 2016)

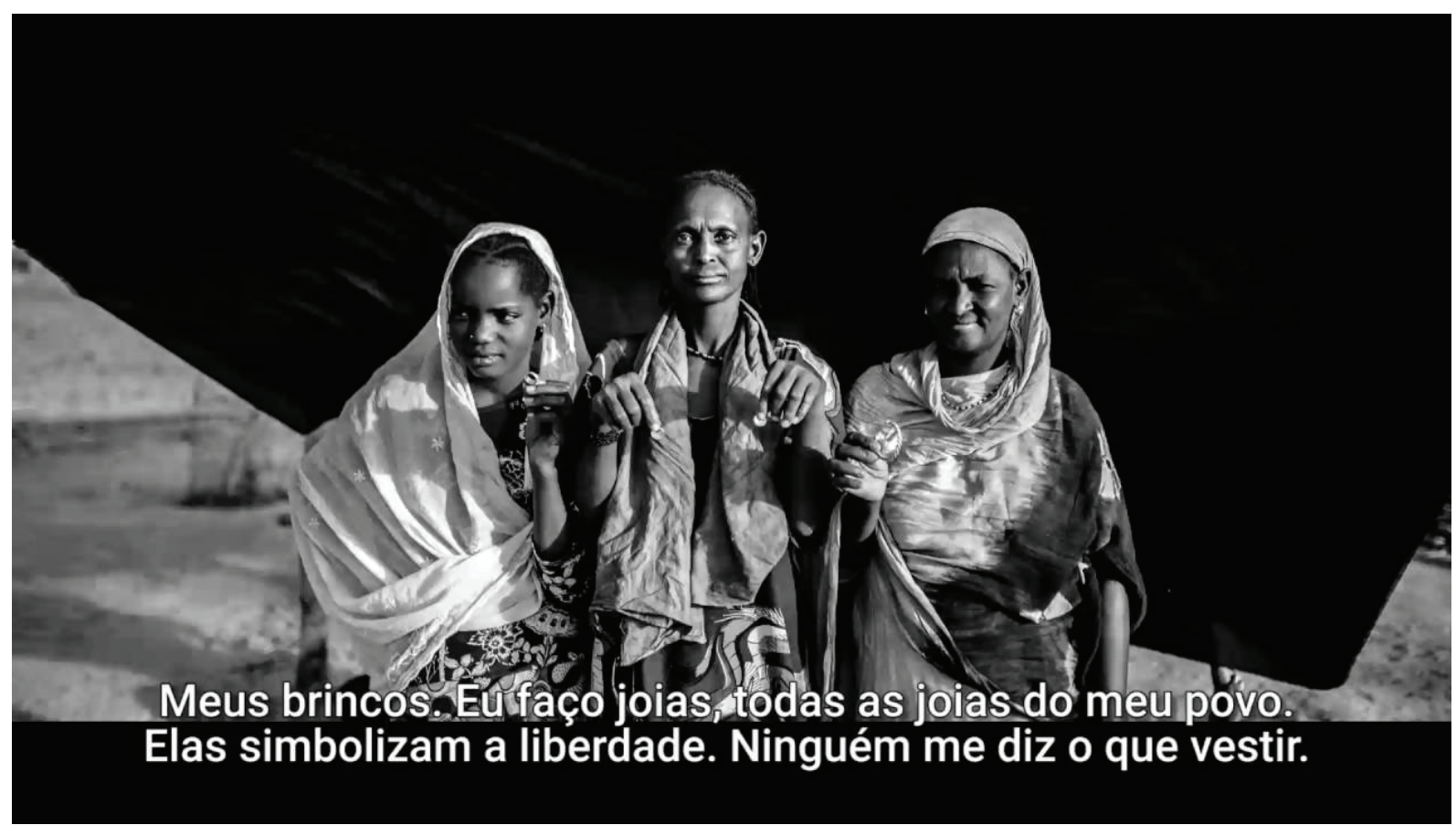

Fonte: https://youtu.be/WV7yM9gQwk4/ 
Desidentificação (Pêcheux, 1988) à língua do outro (deslizamento de sentidos possíveis nos âmbitos verbais e não verbais, no contato com a "língua refugiada").

Nas campanhas digitais $A$ imigração está no nosso sangue (O Globo, 2015) e Eu também sou imigrante, do Ministério da Justiça no Facebook (2015), a desidentificação (deslizamento de sentido) acontece, pois imigrante nem sempre é refugiado (caso dos escravos e operários fabris ou comerciantes, respectivamente).

Figura 4: Descendente de imigrantes ou de escravos?

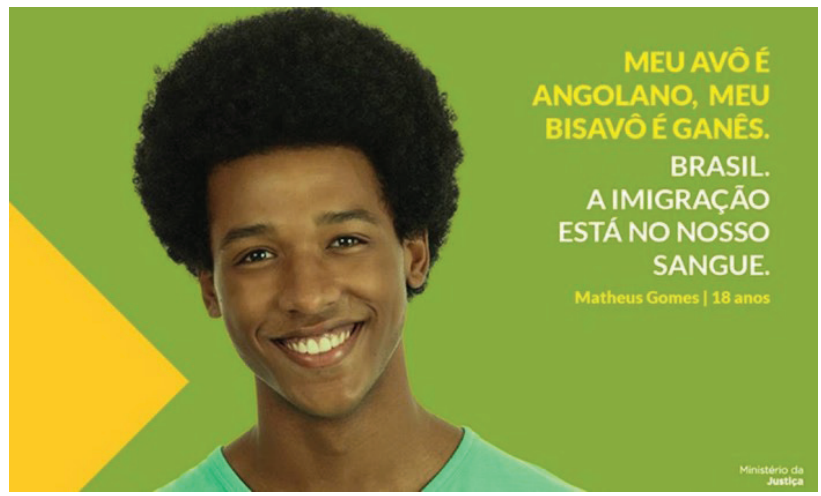

Fonte:https://oglobo.globo.com/sociedade/campanha-do-governocontra-xenofobia-gera-revolta-nas-redes-17772496
O texto da mídia digital (linguagem verbal) na primeira campanha confunde imigração com escravidão de negros, pois, ainda que esta tenha sido abolida no Brasil em 1888, como alegou o Ministério da Justiça em resposta às críticas nas redes sociais, é possível dizer que não são mostrados dados sobre imigração recente dos antepassados referidos nos posts do Facebook do Ministério da Justiça, o que pode / deve levar a significar o passado de escravidão no país. Mas, a linguagem não verbal (a imagem da campanha na rede social) apresenta um jovem negro de camiseta, identificado aos dias atuais por sua idade (Matheus Gomes, 18 anos) e sorrindo, em dissensão de sentido ao significado negativo de escravidão na história nacional. O escravo negro não foi imigrante e nem refugiado, pois não "vem residir ou se fixa num país que não é o seu" (Brasil), porque não tinha direito a possuir casa, terras nem bens. Ele foi levado e induzido a vir. Também não "se afastou do seu local de residência" (África) "para fugir aos efeitos da guerra, das perseguições políticas", estabelecidas entre colonizadores europeus nas Américas (Grande Dicionário Larousse Cultural da Língua Portuguesa, p. 509; p. 776, 1999). A guerra, melhor, a divisão política das Américas não era do seu interesse, não fazia parte do seu contexto histórico, do seu imaginário tribal.

Figura 5: A imigração está no nosso sangue ou em períodos da nossa história?

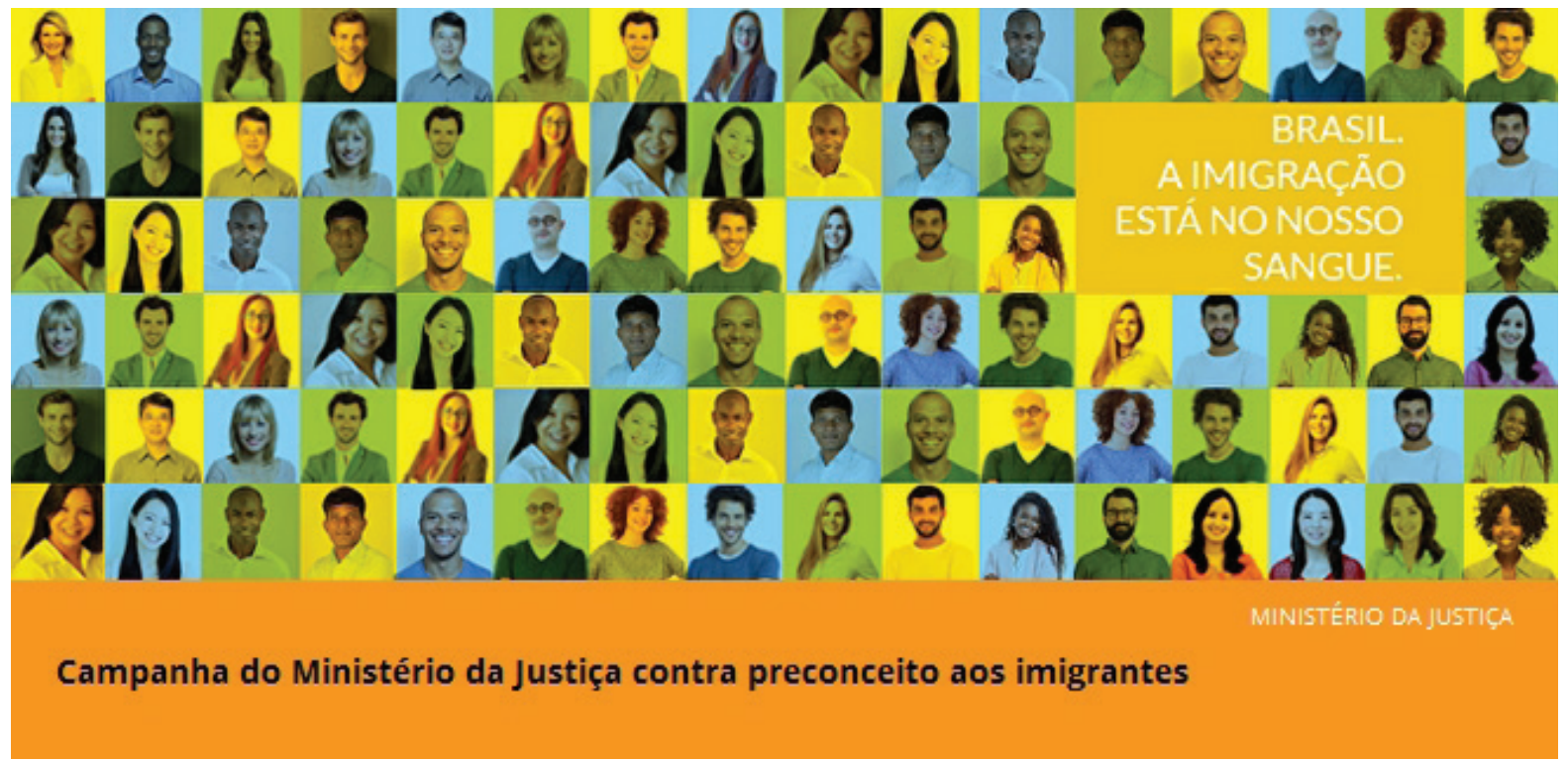

Fonte:https://www.facebook.com/hashtag/eutambemsouimigrante?source=feed_text\&story_id=644996318976282 
Dos 5,5 milhões de escravos que embarcaram para o Brasil 3,86 milhões eram provenientes do centro-oeste africano, que inclui a região onde hoje é Angola, Zaire e Congo, e 877 mil da chamada Costa da Mina, ou golfo do Benim, que inclui parte dos atuais Gana, Togo, Benim e Nigéria, segundo o banco de dados (Soares, 2015).

O bisavô ganês de Matheus pode ter sido escravo e, o avô angolano, um homem alforriado, mas não é possível dizer que são imigrantes nem refugiados.

A campanha é sintetizada em um post que apresenta um painel das pessoas que foram associadas a familiares estrangeiros que chegaram ao Brasil em diferentes momentos da história do país, sem que a relação histórica tenha sido designada e tampouco fazendo referência à questão do refugiado, que é seu produto (objeto de comunicação), como afirma o governo brasileiro (O Globo, 2015).

Por sua vez, na campanha do Ministério da Justiça no Facebook (2015) Eu também sou imigrante, a desidentificação (deslizamento de sentido) também acontece. Neste caso confunde-se imigração com ser cidadão, pois o texto da mídia (o verbal) trata de avôs europeus, mas a imagem do post (não verbal) mostra uma mulher identificada como Graça
Amorim, de 67 anos, sem que esse nome tenha grafia europeia que a identifique como estrangeira que imigrou para o Brasil nem mesmo como refugiada.

Figura 6: Descendente de operários e comerciantes ou a imigrante que afirma ser?

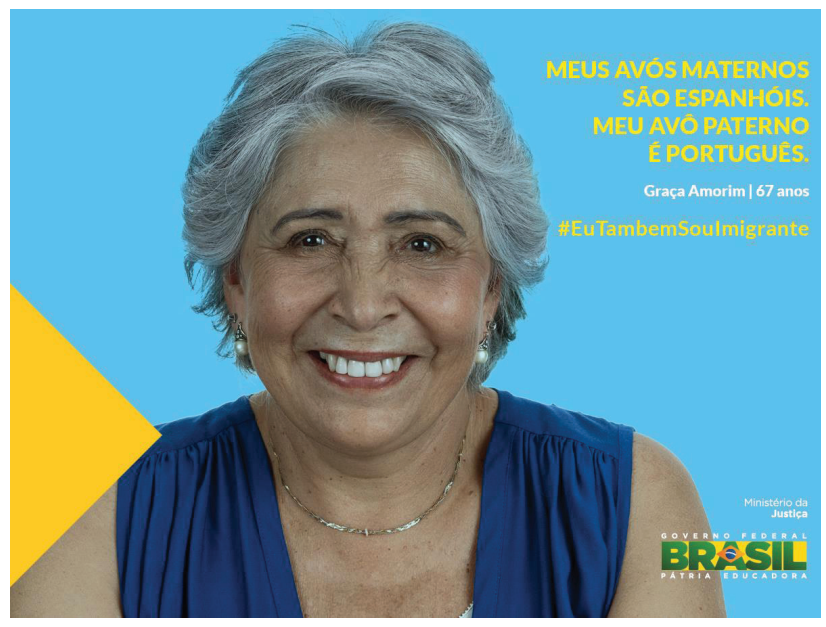

Fonte:https://www.facebook.com/hashtag/eutambemsouimigrante?so urce=feed_text\&story_id=644996318976282

Por mais que uma brasileira queira acolher (seja favorável a) um imigrante (como seus parentes), que se pode / deve inferir terem sido operários de fábricas ou comerciantes desde o século XIX, se ela nasceu no Brasil, ela não é (como eles). Ela também

Figura 7: Participação com post de imigrantes ou de simpatizantes favoráveis a eles?

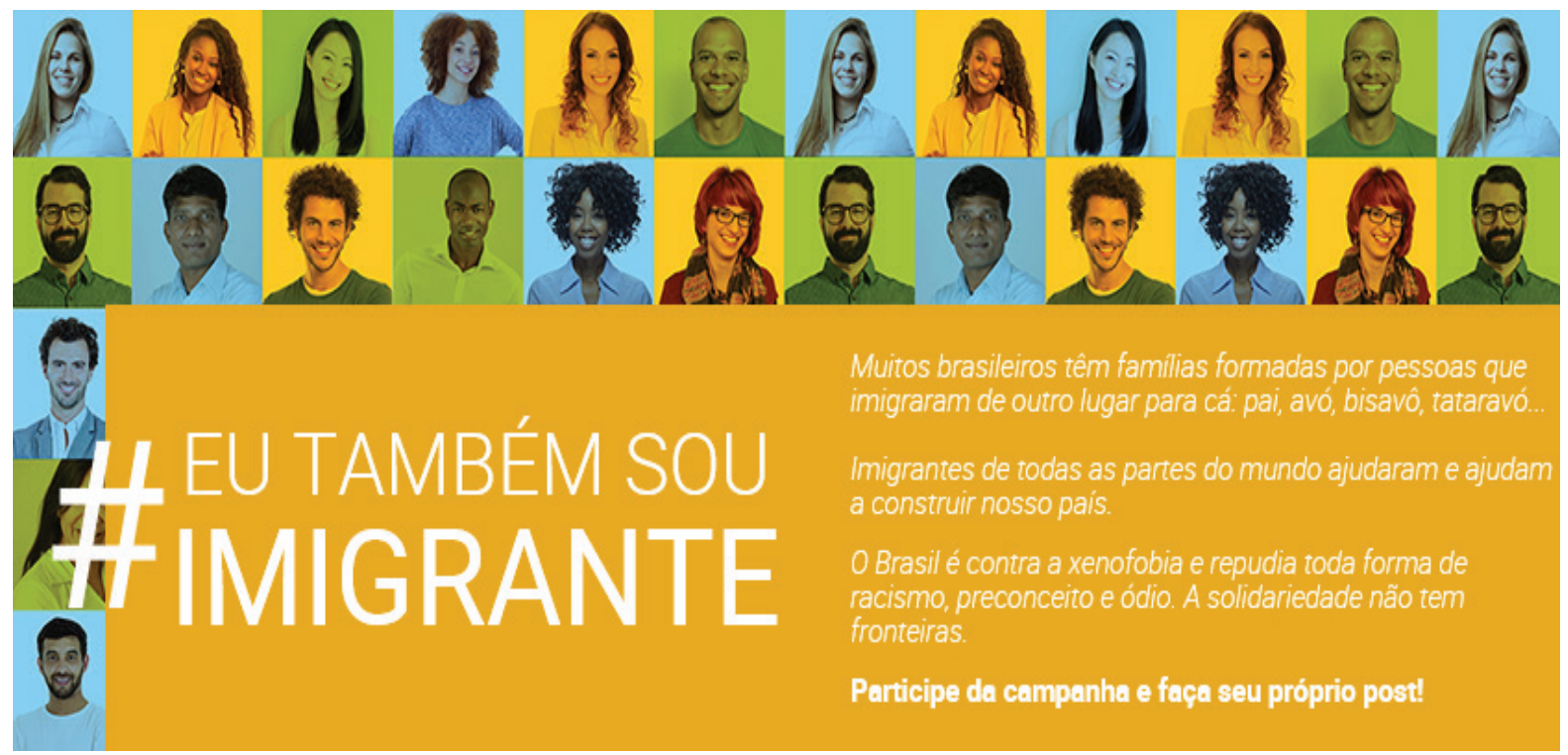

Fonte:https://www.facebook.com/hashtag/eutambemsouimigrante?source=feed_text\&story_id=644996318976282 
pode ser / deve ser pelo imigrante (favorável, acolhedora), mas não é um imigrante, muito menos um Refugiado. A língua estrangeira não se refugia, nesse caso, em seu nome nem nas joias que ela porta. Não se vê formas de argolas, cores pátrias ou ícones que signifiquem o refúgio de um olhar do outro europeu na mulher representada, para além de seu biótipo, seu fenótipo (cor de pele, olhos, cabelos), seus traços fisionômicos.

Além disso, a campanha digital na rede social Facebook, ao estimular os internautas a participarem fazendo um post sobre sua linhagem familiar relacionada a estrangeiros, não contextualiza historicamente a condição do refugiado que é contemporânea à campanha. É o que se vê no post que sintetiza os posts com descendentes apresentados na campanha digital, enfatizando questões como solidariedade e contra a xenofobia, repudiando "toda forma de racismo, preconceito e ódio", sem tocar na segregação específica de uma forma-histórica do sujeito na sociedade capitalista, aquela do refugiado, seja por motivo de guerra, perseguição religiosa e / ou condição de miséria social pelo mundo.

É possível considerar que o sentido dado pela mídia (jornal) e pelo governo (Ministério) nacionais à palavra Imigrante nas campanhas publicitárias digitais funciona como operador discursivo de apagamento (Orlandi, 1997) de outros sentidos históricos negativos sobre o Brasil, tais como escravidão e exploração do trabalho operário europeu. É a língua portuguesa e / ou a outra língua oficial (LIBRAS) que estão em primeiro plano nas campanhas brasileiras. Tudo se passa como se a língua portuguesa é que fosse a "língua refugiada" nas campanhas em que o Refugiado é nomeado de Imigrante.

Ao mesmo tempo, instituições estrangeiras, como UNHCR-ACNUR Américas e ONU, tornam a palavra Refugiado um operador discursivo de valores positivos, atraentes, inclusivos, solidários, como "meu amigo", "somos diferentes" (do Estado Islâmico), com o apelo ao direito à "educação", a marca de "liberdade" no vestir "joias", pois se supõe que em nosso país ninguém interfere com o outro ou diz o que se pode / deve usar.

\section{CONCLUSÕES}

O Panorama da Pesquisa em Comunicação Social no Brasil, com base em Paradigmas (teorias) e Tendências (práticas) abrange desafios para a sociedade de informação (tecnologia) e mercado (consumo) dita globalizada (aspectos político, econômico, tecnológico e psicológico) e, neste estudo, para a sociedade brasileira.

Somos livres desliza para somos cidadãos, pois o povo refugiado-imigrante leva com ele a liberdade cultural, para países considerados livres politicamente (como o Brasil), onde campanhas estrangeiras propagaram a petição de assinaturas pelo direito à educação dos Refugiados - não simplesmente tratados como Imigrantes, como o foram na campanha nacional - em tempos de paz. A língua mostrou-se refugiada na análise das campanhas feitas por instituições estrangeiras (no dizer da mulher síria e nas joias do povo de suposta proveniência africana), como não se mostrou na análise das campanhas sobre refugiados no Brasil (dos parentes de escravos e de operários e comerciantes explorados). A forma do sujeitohistórico imigrante-refugiado no país, no entanto, parece ser o destino comum para ser ou tornar-se diferente (não brasileiro típico) e livre (não escravo africano).

Não se teve a pretensão de esgotar o assunto proposto, pois um panorama e uma análse são, portanto, provisórios e sempre possíveis de sererem outros, a suscitar novos, de acordo com a materialidade do discurso na história e da formasujeito que dele se apropria ao longo do tempo.

\section{AGRADECIMENTOS}

À Profa. Dra. Tania Conceição Clemente de Souza na área de Linguística, Letras e Artes (UNICAMP), professora associada II da Universidade Federal do Rio de Janeiro (UFRJ), lotada no Departamento de Antropologia do Museu Nacional, centro onde desenvolve pesquisa com línguas indígenas e estuda temas sobre análise do discurso, discurso e imagem, análise do não verbal; líder de vários projetos de pesquisa subsidiados por diferentes editais $(\mathrm{CNPq}$ e FAPERJ); coordenadora do Laboratório de Estudos 
do Discurso, Imagem e Som (LABEDIS), vinculado ao Fórum de Ciência e Cultura da UFRJ; e editora de Policromias - Revista de Estudos do Discurso, Imagem e Som, com publicação de artigos de renomados autores nacionais e internacionais. Venho agradecer pela apresentação das questões do discurso na graduação em Comunicação Social da Universidade Federal Fluminense-UFF e pela acolhida da análise do discurso publicitário. À Universidade Salgado de Oliveira - UNIVERSO, campus Niterói, e à Fundação de Apoio à Escola Técnica - FAETEC junto à Escola Técnica Estadual Adolpho Bloch - ETEAB, unidade de São Cristóvão, onde leciono e empreendo pesquisa, respectivamente, sobre o ensino da área e a análise do discurso em comunicação nos cursos superiores de Comunicação Social e médio-técnicos integrados em Marketing e em Publicidade. Ao CNPq, pelo Grupo de Trabalho que associa a docência (UNIVERSO) com os estudos da professora Tânia Souza (UFRJ), e à FAPERJ, quanto ao programa Jovens Talentos que contempla meus orientandos (ETEAB-FAETEC).

\section{REFERÊNCIAS BIBLIOGRÁFICAS}

Benveniste, E. (1995). Comunicação animal e linguagem humana. Problemas de Linguística Geral I. Campinas: Pontes.

Foucault, M. (1996) A ordem do discurso. São Paulo: Loyola.

Grande Dicionário Larousse Cultural da Língua Portuguesa (1999). São Paulo: Nova Cultural, pp. 509 e pp. 776.

Macroplan (2014). Tendências para os próximos 20 anos: mundo, brasil e consumo, 2011. Macroplan. Recuperado de http://www.macroplan.com.br/

O Globo e Facebook (2015). A imigração está no nosso sangue e Eu também sou imigrante. Ministério da Justiça. Recuperado de http:// oglobo.globo.com/sociedade/campanha-dogoverno-contra-xenofobia-gera-revolta-nasredes-17772496 https://www.facebook.com/hashtag/eutamb emsouimigrante? source=feed_text\&story_ id $=644996318976282$

ONG Migraflix (2016). Meu Amigo Refugiado. Recuperado de https://youtu.be/p577E0RwKKw/

Orlandi, E. P. (1997). As formas do silêncio: no movimento dos sentidos. São Paulo: Editora da Unicamp.

Payer, M. O. (2005) Linguagem e sociedade contemporânea: sujeito, mídia e mercado. RUA. Revista do Núcleo de Desenvolvimento da Criatividade da Unicamp XI. NUDECRI. Campinas: Unicamp, 2005, pp. 9-25.

Pêcheux, M. (1988). Semântica e discurso: uma crítica à afirmação do óbvio. Campinas: Editora da UNICAMP.

Pereira, R. da C. (2014). Cibermarketing e Ciberpublicidade: propriedade intelectual, modelos de desenvolvimento produtivo, e pesquisa em marketing e sistemas de informação. Revista Eletrônica Mutações - RELEM. Recuperado de http://www.periodicos.ufam.edu.br/relem/ article/view/574/

Pereira, R. da C. (2008) e Souza, T. C. C. (1994). "Discurso e imagem", texto apostila utilizado no curso "Análise dos sistemas visuais", do Instituto de Arte e Comunicação Social, da Universidade Federal Fluminense - IACS / UFF, 1994. Discurso e publicidade: dos processos de identificação e alteridade pela propaganda brasileira. Tese de Doutorado (UFF, 2005), Niterói: EDUFF (Livro, 2008).

Pereira, R. da C. (2016). Uma análise do discurso sobre megaeventos e consumo: meu Caprichoso e Garantido, meu Brasil no Planeta. Policromias: Revista de Estudos do Discurso, Imagem e Som. UFRJ: Revistas UFRJ, junho / 2016, v. 1, n. 1, 27 pp. Recuperado de https://revistas.ufrj.br/index. php/policromias/article/view/4095/3063

Polistchuk, I. e Trinta, A. R. (2003). Teorias da Comunicação: o pensamento e a prática da Comunicação Social. São Paulo: Campus / Elsevier. 
Soares, M. de C. (2015). Regiões de Angola e Gana destacaram-se no mapa do tráfico de escravos para o Brasil (12/05/2015). Sapo Notícias. Recuperado de https://noticias.sapo.mz/actualidade/artigos/ regioes-de-angola-e-gana-destacaram-se-nomapa-do-trafico-de-escravos-para-o-brasil-2

Souza, T. C. C. e Moura, J. R. F. (2017). Comunicação 14: Refugiados e línguas de herança: plurilinguismo e política de línguas. VI Simpósio Mundial de Estudos da Língua Portuguesa - VI SIMELP - Simpósio 19 - Língua de herança e línguas em contato: pesquisando o convívio entre as línguas minoritárias e língua dominante. Santarém, Portugal. Recuperado de http://simelp. ese.ipsantarem.pt/simposio-19/

Souza, T. C. C. (2016). Línguas indígenas: memória, arquivo e oralidade. Policromias: Revista de Estudos do Discurso, Imagem e Som. UFRJ: Revistas UFRJ, junho / 2016, v. 1, n. 2, 20 pp. Recuperado de https://revistas.ufrj.br/index.php/ policromias/article/view/7710/6228

UNHCR-ACNUR Américas / ONU. (2016). O que levaram com eles. \#ComOsRefugiados. Recuperado de https://youtu.be/WV7yM9gQwk4/ 